\title{
DARK GLASSES
}

BY

F. A. Williamson-Noble

London

DARK glasses for use after intra-ocular operations present rather a problem. The desiderata would appear to be cheapness, lightness, comfort in wear, and exclusion of extraneous light. These were fairly well met before the war by dark glasses with perforated metal side-pieces which came from abroad. Having a flexible frame and side-pieces, they could, by judicious bending and twisting, be made to fit anyone.

These glasses are not procurable now, however, and one has had to rely upon heavier and more expensive types which are not malleable and often require padding with cotton wool or rubber tubing to make them comfortable. It occurred to me that the eye-shield made in large numbers during the war might be useful, if it could be suitably tinted. This was done, but the result was unsatisfactory because of poor ventilation and a tendency for the shield to cockle up. Ventilation was improved by replacing the

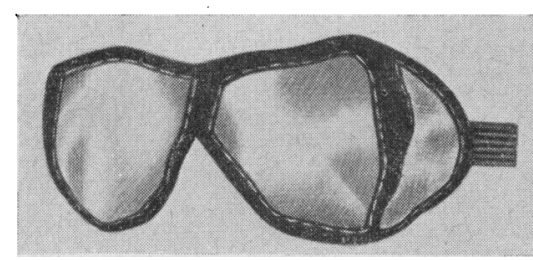

FIG. 1.

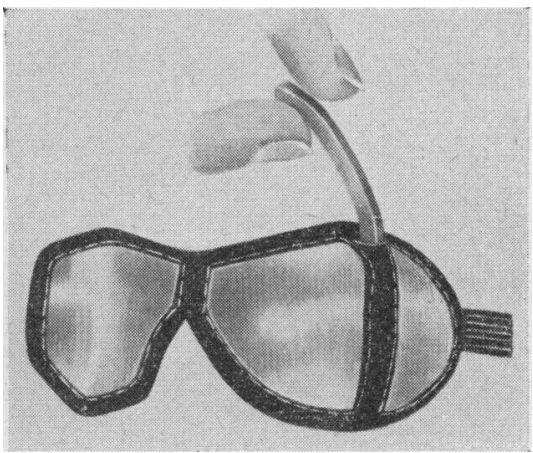

FIG. 2.

lateral portions of the shield with fine wire mesh (Fig. 1), and protective goggles of this type could be worn by patients with a fair degree of comfort. The cockling problem still remained, however, and distortion rendered the goggles unsatisfactory after a few days of wear. This difficulty was surmounted by inserting a small piece of metal into the cloth joining the tinted plastic material to the wire-netting side-pieces (Fig. 2); at the same time the buckle was moved so that it lay at the side of the head, instead of at the back, where it was apt to cause discomfort to a patient lying with the back of his head in contact with the pillow. These goggles have been used by patients with satisfactory results and are relatively inexpensive.

I am grateful to Messrs. Theodore Hamblin for their kind co-operation in making these goggles. 